DOI 10.37882/2500-3682.2021.04.08

\title{
ИСКУССТВЕННЫЙ ИНТЕЛЛЕКТ КАК МЕЖДИСЦИПЛИНАРНЫЙ ФЕНОМЕН
}

\section{PREDICTIVE SIGNIFICANCE OF SELF-ATTITUDE IN THE MODELING OF ARTIFICIAL INTELLIGENCE}

\section{A. Vislova}

Summary: The article analyzes the features of the development of artificial intelligence (Al) in the context of post-nonclassical science. Al is seen as an area of interdisciplinary research. Interdisciplinarity in the context of the problems under consideration is understood as a methodological tool for the theoretical and categorical design of the corpus of scientific disciplines included in the study of artificial intelligence. An attempt was made to comprehend the methodological problems of the interdisciplinary study of Al. The advantages of Al work carried out at the "junction" of scientific disciplines are summarized.

Keywords: artificial intelligence, psychology, post-nonclassical science, interdisciplinary approach, integration, synthesis, synergetics.

\author{
Вислова Аминат Даняловна \\ Д.ncх.н., в.н.с., ФГБНУ «Федеральный научный чентр \\ Кабардино-Балкарского научного чентра \\ Российской академии наук», г. Нальчик \\ avislova@mail.ru
}

Аннотация: В статье анализируются особенности развития искусственного интеллекта (ИИ) в контексте постнеклассической науки. ИИ рассматривается как область междисциплинарных исследований. Междисциплинарность в контексте рассматриваемой проблематики понимается как методологический инструмент теоретического и категориального оформления корпуса научных дисциплин, включенных в исследование искусственного интеллекта. Предпринята попытка осмысления методологических проблем междисциплинарного изучения ИИ. Обобщаются преимущества работ по ИИ, выполненных на «стыке» научных дисциплин.

Ключевые слова: искусственный интеллект, психология, постнеклассическая наука, междисциплинарный подход, интеграция, синтез, синергетика.

ботах Б.М. Величковского, М.В. Фаликман, В.А. Мазилова, В.Е. Клочко, А.А. Крылова, Е.Н. Князевой, Б.М. Кедрова и др.

Междисциплинарность в контексте рассматриваемой проблематики нами понимается как методологический инструмент теоретического и категориального оформления корпуса научных дисциплин, включенных в исследование искусственного интеллекта.

Когда актуализируется проблема междисциплинарной интеграции? Согласимся с Б.М. Величковским, который поясняет, что «роль интегративных течений увеличивается тогда, когда становится очевидной фрагментарность результатов: дальнейшее аналитическое движение на отдельном участке не приводит более к лучшему понимания природы («природы» в широком смысле слова, включающем в себя человека и общество) и становится контрпродуктивным» [3].

Междисциплинарный подход стал научным трендом начиная с последней четверти XX в. и связан со становлением постнеклассической рациональности.

Что из себя представляет постнеклассическая рациональность и чем она отличается от других периодов развития науки?

Первая научная концепция об этапах развития науки, или трех типах рациональности, была предложена 
академиком В.С. Стёпиным. Сегодня она стала достоянием широкой академической общественности и активно цитируется учеными разных областей знания. Степень популярности и влияния концепции на науку позволяет говорить о том, что она содержит значительный потенциал для анализа особенностей развития науки. Известный ученый вводит идею о необходимости различать классическую (XVII-XIX вв.), неклассическую (XXв.) и постнеклассическую (конец XX в., настоящее время) науку. В качестве основных критериев выделенных типов рациональности указываются:

1. «особенности системной организации исследуемых объектов и типов картины мира;

2. особенности средств и операций деятельности, представленных идеалами и нормами науки;

3. особенности ценностно-целевых ориентаций субъекта деятельности и рефлексии над ними, выраженные в специфике философско-мировоззренческих оснований науки» [4]. По сути, сегодня не существует более логичной типологии, четко отражающей динамику развития науки.

Не останавливаясь подробно на временной локализации всех типов, отметим, что классическая и неклассическая науки, как правило, «имеют дело с фиксацией свойств и зависимостей объектов, и только постнеклассическая имеет дело с реальностью, которая затрагивает и объекты, и человеческий мир» [5]. Существенный штрих концепции - это представление о мире как целостном образовании.

Постнеклассическая парадигма - это не «чисто познавательная рациональность, претендующая на моделирование реальности «как она есть», она выступает как форма ... проектно-конструктивной рациональности» [6]. Действительно, постнеклассическая наука открывает новые перспективы и предлагает рассмотреть феномены под иным углом зрения.

Ключевыми признаками постнеклассического этапа развития науки являются:

- изменение характера научной деятельности, обусловленное революцией в средствах получения и хранения знаний (компьютеризация науки, сращивание науки с промышленным производством и т.п.);

- распространение междисциплинарных исследований и комплексных исследовательских программ;

- изменение самого объекта - открытые саморазвивающиеся системы;

- включение аксиологических факторов в состав объясняющих предложений [7].

Главной особенностью постнеклассической науки является изучение сверхсложных систем, соотнесен- ность получаемых знаний не только со средствами деятельности, но и с ценностно-целевыми структурами. Закономерно это предполагает «обобщающее понимание науки как единства многообразия в процессе восходящего развития науки» [8].

Основанием постнеклассического типа рациональности признается синергетика. Однако, высказываются возражения относительно оправданности рассматривать синергетику в качестве ядра постнеклассической науки, объясняя это тем, что «синергетика явно не смогла предложить альтернативную картину мира. Все разговоры про возникаемость, холизм и нисходящую причинность остались только разговорами» [9]. Любая смена парадигмы, любые содержательные изменения в теориях сопряжены с неоднозначной оценкой учеными происходящих перемен. Поэтому критический взгляд на возможности синергетики вполне вписывается в такую традицию.

Постнеклассическую науку отличает ее способность объяснить возникновение новых феноменов и фактов, интерпретировать их с междисциплинарных позиций. Для неё характерно «соединение идеи эволюции с идеями системного подхода» и «установление универсальной связи между неживой, живой и социальной материей [10]. Указанная универсальность дает основание утверждать, что она применима и в междисциплинарном изучении актуальных проблем искусственного интеллекта.

В части разработки проблематики искусственного интеллекта активно обсуждается роль психологии в междисциплинарном исследовании в контексте постнеклассической науки. С одной стороны, это чревато ускоренным и недостаточно адаптированным включением психологических терминов и понятий в методологический аппарат ИИ (хотя этот процесс идет стихийно давно), а с другой стороны, с неизбежностью это обусловит и обратное движение - неправомерное вторжение технической и иной терминологии в психологическую науку.

В данном случае представляется справедливой точка зрения В.Е. Клочко, который возражает против пересадки новых и недостаточно отрефлексированных познавательных установок на почву психологии без их согласования с постнеклассическим потенциалом, накопленным в культурно-исторической теории Л.С. Выготского [11]. Добавим к этому, что фрагменты постнеклассической рациональности содержатся и в других концептуальных представлениях и психологических теориях. Однако ограничимся только упоминанием, поскольку обсуждение этого вопроса в контексте заявленной в статье проблемы не представляется возможным. Вместе с тем, согласимся с утверждением С.Ф. Сергеева 
о том, что «в существующей форме постнеклассическая психология представляет собой довольно пестрый, недостаточно хорошо структурированный научный дискурс» [12]. Одним словом, современной психологии необходима методологическая рефлексия относительно постнеклассической парадигмы в плане логик исследования сложно системных феноменов.

Постнеклассическая психология находится в начале пути к развитию междисциплинарных исследований. Можно предположить, что большинство «узких» дисциплин находятся на этом же уровне развития междисциплинарности. Только когнитивная наука добилась существенных результатов в данном направлении и, в особенности, при рассмотрении проблемы искусственного интеллекта.

Исходя из изложенного, можно констатировать, что «с воцарением постнеклассической парадигмы перед наукой и человечеством в целом стоит ряд глобальных вопросов, решение которых в исторической практике пока не выработано» [13]. Одной из масштабных проблем является искусственный интеллект и возможные новые научные открытия в этой области находятся в зоне междисциплинарных исследований.

Обратим внимание, что отдельно взятая дисциплина рассматривает любую научную проблему под своим углом зрения. Наряду с этим, проведение исследования, «выходящего за рамки дисциплинарных ограничений, является сложной задачей, особенно потому, что дисциплины воплощают в себе очень разные способы познания» [14].

Междисциплинарная интеграция, как правило, противопоставляется дисциплинарной дифференциации и сегментации науки как процесс обмена элементами когнитивного содержания между дисциплинами, позволяющий повышать их познавательную эффективность в ходе исследований, т.е. создавать новое знание. В этот обмен могут вовлекаться как методологические, так и теоретические компоненты дисциплин, которые адаптируются к когнитивному содержанию других дисциплин. Содержание, устойчивость и интенсивность этих обменов может быть различной и влиять на характер междисциплинарной интеграции $[15,16]$. По сути, междисциплинарность «раздвигает» дисциплинарные границы, «исправляет» отдельные последствия чрезмерной специализации научных дисциплин [17], является выражением «интегративного характера современного этапа научного познания» [18]. Проведение междисциплинарных исследований сопряжено с рядом сложностей. Одна из них заключается в «несовпадении специализированных языков, а также понятийного аппарата различных дисциплин» [19]. Это наводит на мысль о том, что при изучении ИИ с междисциплинарных позиций изначально необходимо согласовать основополагающие понятия и термины, методологические установки. Тем более, что идеи междисциплинарных исследований в области искусственного интеллекта отличаются значительной масштабностью.

В основе междисциплинарности лежит «идея синтеза и интеграции знаний, возраст которых составляет, пожалуй, не одно тысячелетие» [20].

Касаясь проблемы исследований на «стыке» наук, важно отметить, что «междисциплинарность - это: не собрание группы экспертов, каждый из которых эксперт «во всем»; не собрание людей из разных областей знаний в одном месте; не создание всех инструментов для всех дисциплин, а: установление связей, которые позволяют отфильтровать главную (инновационную) идею; отфильтрованная идея создает информацию, которая полезна для всех участников проекта; полезная информация есть знание, которое является богатством [21]. Развитие ИИ идет по пути все большего усложнения и указанные характеристики позволяют правильно определить векторы развития междисциплинарности в этой области науки.

Что же касается основных акцентов, определяющих успешность междисциплинарных проектов, то они заключаются в адекватном задачам исследования ИИ взаимном применении концепций, методов и средств, которыми апеллирует каждая дисциплина. Только в этом случае ожидаемые новые научные данные могут быть реалистичными.

В современном мире объем новых знаний постоянно растёт и вполне понятна привязанность ученых к своим «узким» наукам, нерешительность в выборе междисциплинарной парадигмы с множеством неопределенностей. Однако решение таких сложносистемных проблем как ИИ не оставляет никаких шансов избежать междисциплинарное сотрудничество. Тем более, что такая совместная деятельность ведет к взаимному обогащению наук. «Основным назначением междисциплинарной работы является объединение соответствующих знаний для решения серьезной проблемы» [22].

И вряд ли может вызвать возражение утверждение о том, «что самые значительные успехи достигались тогда, когда перебрасывались мостики между различными дисциплинами [23]. В качестве возможных вариантов развития междисциплинарных исследований выделяются следующие:

1. Проблема успешно решается. Исследователи в этом случае переключаются на другие проблемы моно- или междисциплинарного характера;

2. Завершение междисциплинарного исследования в некоторой проблемной области приводит к воз- 
никновению новой научной дисциплины. Это происходит, если перманентная проблематика осознается методологически, т.е. создается научная теория объектов определенного класса, а также фиксированные методы их изучения. Институциональным завершением данного цикла являются возникновение единого, связанного взаимным цитированием массива публикаций, и подготовка специалистов в новой научной области. В этом случае имеет место фактическое прекращением междисциплинарных исследований - новая область становится самостоятельной дисциплиной, являясь междисциплинарной лишь по генезису и обычно по названию. Классическим примером такого пути является возникновение экономической социологии.

3. Третий путь реализуется, когда междисциплинарные исследования в какой-либо области продолжаются десятки лет. С такой ситуацией мы имеем дело в крупных исследовательских проектах, когда сохраняется некоторая проблемная область, требующая целой серии междисциплинарных исследований. В качестве примера здесь может выступать изучение взаимоотношений культуры и экономических систем [24]. Преобладание того или иного пути развития зависит от цели и форм реализации междисциплинарности.
В заключение отметим, что междисциплинарный подход представляет собой решение научных проблем, основанный на объединении нескольких научных дисциплин под эгидой определенной обобщающей концепции в целях получения новых данных по исследуемой проблеме.

Искусственный интеллект является одним из наиболее успешных междисциплинарных проектов. Междисциплинарность в контексте проблематики искусственного интеллекта можно рассматривать как методологический инструмент теоретического и категориального оформления корпуса научных дисциплин, включенных в данный исследовательский дискурс.

В целом, тенденцией современной науки является все большее распространение междисциплинарных исследований, выполняемых на «стыке» наук в целях решения актуальных научных проблем. Так, потребность в изучении различных феноменов искусственного интеллекта потребовала привлечения знаний из разных научных направлений и интеграции ряда наук. Результативность междисциплинарной деятельности зависит от усилий каждого «узкого» специалиста. Их концептуальные идеи, выбор адекватных исследовательских методов определяют перспективность междисциплинарной парадигмы в изучении искусственного интеллекта.

\section{ЛИТЕРАТУРА}

1. Вернадский В.И. Философские мысли натуралиста. М.: Наука, 1988. С. 124.

2. Энциклопедия по машиностроению. URL: http://mash-xxl.info/info/ 477089/ (дата обращения: 03.04.2021).

3. Величковский Б.М. Когнитивная революция и человек будущего. URL: https://polit.ru/article/2007/02/08/velichkovskiy/ (дата обращения: 03.03.2021).

4. Социологический словарь / сост.: А.Н.Елсукова, К.В. Шульга. - 2-е изд. Минск: Университетское, 1991. $528 c$.

5. Воронка Р.А. Особенности постнеклассической науки: философский аспект // Філософія науки: традиції та інновації, 2017. № 2 (16). С. 73.

6. Цикин В.А. Проблема смены гносеологической парадигмы // Практическая философия, 2004. № 1. С. 162-166.

7. Степин В.С. Классика, неклассика, постнеклассика: критерии различения // Постнеклассика: философия, наука, культура. СПб. ИД «Міръ», 2009. С. 249295. URL: http://iphras.ru/uplfile/root/stepin/klassika,_neklassika,_iostneklassika.pdf (дата обращения: 18.03.2021).

8. Прохоров М. М. Наука и современность// Философия и общество, 2013. Выпуск №1(69). С.86-104.

9. Рудный Е. Что такое постнеклассическая наука? URL: http://blog.rudnyi.ru/ru/2020/01/chto-takoe-postneklassicheskaya-nauka.html (дата 06ращения:19.03.2021).

10. Цикин В.А. Проблема смены гносеологической парадигмы// Практическая философия, 2004. № 1. С. 162-166.

11. Клочко В.Е. Постнеклассическая трансспектива психологической науки // Вестник ТГУ. 2007. № 305. С. 157-164.

12. Сергеев С.Ф. Постнеклассическая рациональность в психологии // Психологический журнал, 2020. T. 41. № 3 С. 131-134. D0I: 10.31857/S0205959200093376. URL: http://ras.jes.su/psy/s020595920009337-6-1 (дата обращения: 19.03.2021).

13. Буданов В.Г. Синергетическая парадигма и её творцы // Сложность. Разум. Постнеклассика. 2018. №3. С.56-72.

14. Carter M. Ways of knowing, doing and writing in the disciplines. College Composition and Communication, 2007. P. 385- 418.

15. Interdisziplinarität. Theorie, Praxis, Probleme / Jungert M., Romfeld E., Sukopp T., Voigt U. (eds.). - Darmstadt: WBG, 2010. 209p.

16. The Oxford handbook of interdisciplinarity / Frodeman R., Klein T., Mitcham J. (eds.). - Oxford: Oxford univ. press, 2010. 624 p.

17. Книгин В.А. Междисциплинарность: основная проблема // Вестник Томск. гос. ун-та. Философия. Социология. Политика, 2008. № 3 (4). С. $14-19$.

18. Гусев С.С. Междисциплинарность// Энциклопедия эпистемологии и философии науки / Гл. ред. И.Т. Касавин. — М.: Канон+, 2009. С. $477-478$.

19. Лысак И.В. Междисциплинарность: преимущества и проблемы применения//Современные проблемы науки и образования, 2016. № 5. URL: http:// science-education.ru/ru/article/view?id=25376 (дата обращения: 03.04.2021).

20. Klein J. Th. Interdisciplinarity: History, theory, and practice / Julie Thompson Klein. - Detroit: Wayne State Uni. Press, 1990. 331 p. 
21. Lori Nicolas Francisco. Междисциплинарность в инженерном образовании: тенденции и концепции // Инженерное образование, 2014. Вып. 14. С. $31-37$.

22. McGrath, Earl J. Interdisciplinary studies: An integration of knowledge and experience // Change: The Magazine of Higher Learning, 1978. Vol. 10. P. 6-9.

23. Алле М. Экономика как наука / Пер. с фр. М., 1995. С. 49.

24. Мирский Э.М., Петров М.К. Междисциплинарные исследования в структуре научно-технического прогресса// Проблемы деятельности ученого и научных коллективов. Сб. научных трудов. - Л., 1973. Вып. V. С. 141-145.

\section{( Вислова Аминат Даняловна (avislova@mail.ru)}

Журнал «Современная наука: актуальные проблемы теории и практики»

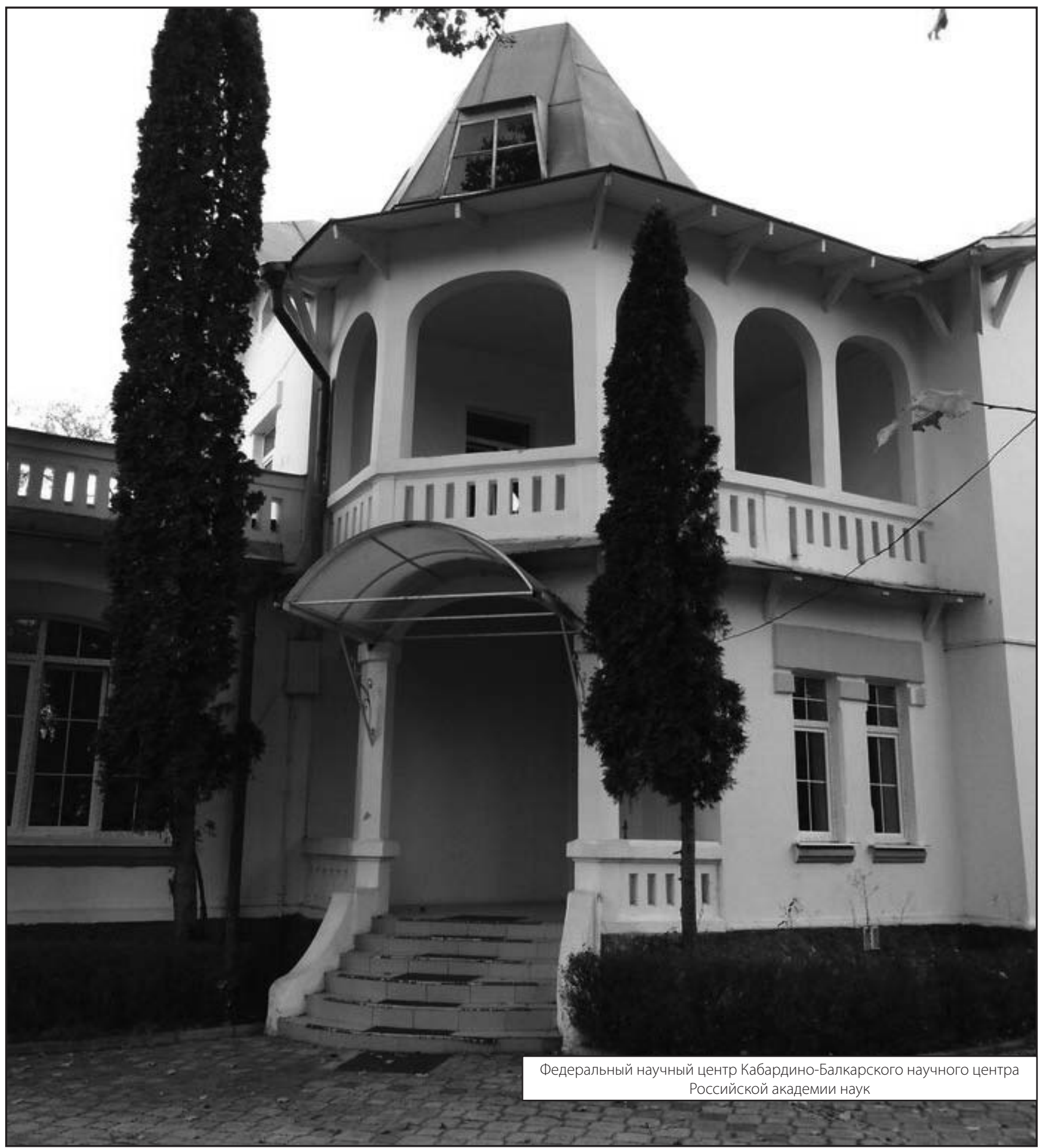

